\title{
Lentinan inhibits tumor angiogenesis via interferon $\gamma$ and in a T cell independent manner
}

Shengming Deng ${ }^{1 \dagger}$, Guoxi Zhang $^{2 \dagger}$, Jiajie Kuai ${ }^{1}$, Peng Fan' ${ }^{1}$ Xuexiang Wang ${ }^{1}$, Pei Zhou ${ }^{1}$, Dan Yang ${ }^{3}$, Xichen Zheng ${ }^{1}$, Xiaomei Liu', Qunli $\mathrm{Wu}^{3^{*}}$ and Yuhui Huang ${ }^{1 *}$

\begin{abstract}
Background: Antiangiogenic agents are commonly used in lung and colon cancer treatments, however, rapid development of drug resistance limits their efficacy.

Methods: Lentinan (LNT) is a biologically active compound extracted from Lentinus edodes. The effects of LNT on tumor angiogenesis were evaluated by immunohistochemistry in murine LAP0297 lung and CT26 colorectal tumor models. The impacts of LNT on immune cells and gene expression in tumor tissues were determined by flow cytometry, qPCR, and ELISA. Nude mice and IFNy blockade were used to investigate the mechanism of LNT affecting on tumor angiogenesis. The data sets were compared using two-tailed student's $t$ tests or ANOVA.

Results: We found that LNT inhibited tumor angiogenesis and the growth of lung and colon cancers. LNT treatments elevated the expression of angiostatic factors such as IFNY and also increased tumor infiltration of IFNy-expressing T cells and myeloid cells. Interestingly, IFNy blockade, but not T cell deficiency, reversed the effects of LNT treatments on tumor blood vessels. Moreover, long-lasting LNT administration persistently suppressed tumor angiogenesis and inhibited tumor growth.

Conclusions: LNT inhibits tumor angiogenesis by increasing IFNy production and in a T cell-independent manner. Our findings suggest that LNT could be developed as a new antiangiogenic agent for long-term treatment of lung and colon cancers.
\end{abstract}

Keywords: Lentinan, Interferon $\gamma$, Antiangiogenic therapy, Drug resistance, Lung cancer

\section{Background}

New blood vessels must be developed to nourish tumors that grow bigger than $2 \mathrm{~mm}^{3}$ in volume, and the tumor vasculature is also a necessity for a tumor's ability to metastasis; angiogenesis is thus a hallmark of cancer [1,2]. Important proangiogenic factors that are known to be involved in tumor angiogenesis include proteins of the vascular endothelial growth factor (VEGF) family, the

\footnotetext{
* Correspondence: chinlie@163.com; huangyh@suda.edu.cn

†'Shengming Deng and Guoxi Zhang contributed equally to this work.

${ }^{3}$ Department of Traditional Chinese Medicine, Peking Union Medical College Hospital, Peking Union Medical College and Chinese Academy of Medical

Sciences, No. 1 Shuaifuyuan, Dongcheng District, Beijing 100730, China

${ }^{1}$ Cyrus Tang Hematology Center, Collaborative Innovation Center of Hematology, State Key Laboratory of Radiation Medicine and Prevention, Soochow University, 199 Ren-Ai Road, Suzhou 215123, Jiangsu, China Full list of author information is available at the end of the article
}

platelet-derived growth factor (PDGF) family, the fibroblast growth factor (FGF) family, and placental growth factor (PlGF) [1, 3]. Therefore, the blockade of proangiogenic signaling pathways has been investigated and developed as an antiangiogenic therapy aiming to starve tumor cells to death [3-6].

Antiangiogenic therapies are currently in wide use against non-small cell lung cancer (NSCLC), colorectal cancer, and several other types of solid tumors [1,3]. The first antiangiogenic agent approved for NSCLC was bevacizumab, a monoclonal antibody to VEGF-A. The combination of bevacizumab and chemotherapeutic agents, such as carboplatin and paclitaxel, improved both progression-free survival and overall survival in advanced NSCLC patients, compared with chemotherapy alone [4]. However, the clinical benefits from VEGF inhibitors are modest and transient, 
and are usually followed by the rapid emergence of drug resistance $[1,3,6]$. As compensatory proangiogenic factors, such as PDGF and FGF, play key roles in mediating the resistance to VEGF signaling blockade therapy, multiple targeted kinase inhibitors (TKIs) could circumvent the common problem of rapid drug resistance onset because they simultaneously block several signaling pathways $[1,3]$. The development of multitargeted TKIs is expected to combat this resistance, however, there have been few convincingly studies in the clinic to date [1,7]. Moreover, marginal survival benefits and significant toxicities associated with TKIs have limited enthusiasm for this therapeutic approach. Therefore, a new strategy to better control tumor angiogenesis remains much anticipated.

Several recent reports suggest that immune stimulation can also restrict tumor angiogenesis. Activated $\mathrm{T}$ cells have been shown to decrease tumor vessel density, inhibit tumor endothelial cell proliferation, and/or arrest tumor blood flow [8-12], suggesting immune stimulators might have the capability to inhibit tumor angiogenesis. Lentinan (LNT), a biologically active compound extracted from Lentinus edodes (L. edodes), is an immunopotentiator [13-15], and exhibits multiple biological activities, including immunomodulatory, antibacterial, antivirus, antitumor effects, and anti-inflammatory [14, 16-19]. Although the combination of LNT with TNP-470 (TNP), an angiogenic inhibitor, displayed antiangiogenic effects and promoted tumor cell apoptosis [20], whether LNT affects tumor angiogenesis remains unclear. In this study, we evaluated the effects of LNT on the tumor vasculature in LAP0297 lung carcinoma and CT26 colorectal carcinoma. LNT treatments significantly reduced tumor vascular function and inhibited tumor growth. Moreover, long-term LNT treatments continuously suppressed tumor angiogenesis and exhibited antitumor effects. Mechanically, LNT inhibited tumor angiogenesis via IFN $\gamma$ up-regulation, which was associated with the accumulation of tumorinfiltrating myeloid cells. Thus, this study demonstrates the potential of LNT to be served as a novel antiangiogenic agent for long-term cancer treatments.

\section{Methods}

\section{Materials and reagents}

The Lentinan (LNT, $1 \mathrm{mg}, 16100108$ ), a gift from Nanjing Luye pharmaceutical Co., Ltd. (Nanjing, China), is provided as powder in a penicillin bottle. LNT was dissolved in saline $(0.9 \% \mathrm{NaCl})$ right before in vivo administration.

\section{Tumor models}

Female FVB mice (6-8 weeks old) were bred and maintained in the gnotobiotic laboratory animal center in Soochow University. Female BALB/c and nude mice (6-8 weeks old) were purchased from the Shanghai Laboratory Animal Center (Shanghai, China) and the Vital
River Laboratories (Beijing, China), respectively. All of the mice were housed in the specific pathogen-free (SPF) condition. FVB and Balb/c mice were subcutaneous (s.c.) inoculated with $2 \times 10^{5}$ cells of LAP0297 or CT26 on the right flanks, respectively. When tumors reached $4-5 \mathrm{~mm}$ in diameter, mice bearing tumors were randomly divided into appropriate groups and subjected to Lentinan or saline $(0.9 \% \mathrm{NaCl})$ treatments. In the long-term treatment experiments, mice bearing tumors were euthanized when tumor volume exceeded $1000 \mathrm{~mm}^{3}$. Tumor volume $\left(\mathrm{mm}^{3}\right)$ was estimated by using the following formula: tumor volume $=($ long axis $) \times(\text { short axis })^{2} \times \pi / 6$.

\section{Cell lines}

The LAP0297 lung carcinoma cell line was generated by Dr. Peigen Huang at Massachusetts General Hospital (Boston, USA) [21]. The CT26 tumor cell line was purchased from the American Type Culture Collection. Tumor cells were cultured in Dulbecco's modified Eagle's medium (DMEM) (GIBCO) supplemented with 10\% heat-inactivated fetal bovine serum (FBS) (GIBCO) and $1 \%$ penicillin and streptomycin (GIBCO) at $37{ }^{\circ} \mathrm{C}$ in a humid incubator containing $5 \% \mathrm{CO}_{2}$. Cell cultures were frequently monitored for mycoplasma contamination, and only mycoplasma-negative cells were used for experiments.

\section{Tumor vascular function analysis}

The function of tumor blood vessels was determined by analyzing the intensity of Hoechst 33342 (Sigma), as described previously [22]. Briefly, $5 \mathrm{~min}$ after intravenous injection of Hoechst $33342(10 \mathrm{mg} / \mathrm{kg})$, mice were systemically perfused with PBS, and the tumors were removed and fixed with $4 \%$ paraformaldehyde. This procedure labeled functional vessels with fluorescence of nucleus-bound Hoechst 33342. Mosaic images of tumors were taken using an Olympus FV1000 confocal laser-scanning microscope. A $20 \times$ objective acquired $640 \times 640 \mu \mathrm{m}$ tiles, and an automated stage scanned through the entire cross section of a tumor tissue. The imaged tiles were stitched into a final mosaic image using an Olympus software. Nonspecific nuclear staining (Sytox green from Molecular Probes) was used to counter-stain the slides. In each field, the intensities of CD31 and Hoechst 33342-positive areas were calculated using an Image-Pro plus software (version 6.0).

\section{Immunohistochemistry}

Tumor tissue samples were fixed for $2-3 \mathrm{~h}$ in $4 \%$ paraformaldehyde, and then incubated with $30 \%$ sucrose in PBS overnight at $4{ }^{\circ} \mathrm{C}$. The tissue samples were then embedded in optical coherence tomography (OCT) compound and stored at $-80^{\circ} \mathrm{C}$. Frozen sections $(20 \mu \mathrm{m})$ were incubated with a primary rat anti-mouse CD31 antibody (endothelial cell marker, 1:100, Clone MEC13.3, Cat\#: 550274, BD 
Biosciences) and a secondary Alexa Fluor 647 donkey anti-rat IgG antibody (1:200, Jackson ImmunoResearch) to stain endothelial cells. The slides were counter-stained for cell nuclei by Sytox Green (Molecular Probes). Fluorescent images were taken using an Olympus FV1000 confocal laser scanning microscopy. Four to six photographic areas, excluding the tumor periphery, were randomly taken from each tumor tissue $\left(640 \times 640 \mu \mathrm{m}^{2}\right.$ each). Mean fluorescence intensity (MFI) of CD31 positive and Hoechst 33342 stained areas were calculated using an Image-Pro plus software (version 6.0).

\section{Tube formation assays}

Tube formation assay was used to evaluate the effect of LNT on endothelial cells as descried previously with minor modifications [23, 24]. Briefly, human umbilical vein endothelial cells (HUVECs) were cultured in DMEM medium containing 10\% FBS. Growth factor reduced matrigel matrix (CORNING) was placed in a refrigerator $\left(4{ }^{\circ} \mathrm{C}\right)$ overnight to thaw the matrigel. Plates (24-well) were coated with $100 \mu \mathrm{l} /$ well of matrigel matrix and were incubated at $37{ }^{\circ} \mathrm{C}$ for 30 min to allow the gel to solidify. HUVECs (30,000 cells/well) were seeded onto the top of the gel and were treated with different concentrations of LNT for $12 \mathrm{~h}$ in triplicate at $37{ }^{\circ} \mathrm{C}$ with $5 \% \mathrm{CO}_{2}$. The process of tube formation was monitored every $3 \mathrm{~h}$ and the pictures were taken by using a Box-Type Fluorescence Imaging Device (OLYMPUS). The numbers of the tubes and branches in each well were counted.

\section{Quantitative real-time PCR}

Total RNA from tumor tissues was isolated by a MicroElute Total RNA kit (Omega), followed by cDNA synthesis with a RevertAid First Strand cDNA Synthesis Kit (Thermo Scientific). The levels of related mRNA were determined by using a high-throughput fluorescence quantitative PCR meter (LightCycler480 II) (Roche). The primers (Table 1) were specifically designed to avoid nonspecific amplification by one half hybridizing to the 3 ' end of one exon and the other half hybridizing to the $5^{\prime}$ end of the adjacent exon. Beta-actin was used as a reference gene to calculate the differences in gene expression (fold change).

\section{Flow cytometry analysis}

Mice bearing tumors were intracardially perfused with PBS. Tumor tissues were isolated and single cell suspensions were prepared by using the digesting DMEM medium containing collagenase type $1 \mathrm{~A}(1500 \mathrm{U} / \mathrm{ml})$, hyaluronidase $(1000 \mathrm{U} / \mathrm{ml})$ and DNase $(20 \mathrm{U} / \mathrm{ml})$. Rat anti-mouse CD16/CD32 monoclonal antibody was added into the single-cell suspensions before other antibody staining. After staining, cells were washed with cold flow buffer (1\% BSA, $0.1 \% \mathrm{NaN}_{3}$ in PBS), and 7AAD reagent (eBioscience) was added ( $5 \mathrm{ul} /$ tube) prior to running the
Table 1 Primers used for qPCR analysis

\begin{tabular}{lll}
\hline Gene & Primer & Sequence (5'-3') \\
\hline$\beta$-actin & Forward & ATCGTGCGTGACATCAAAGA \\
& Reverse & ACAGGATTCCATACCCAAGAAG \\
Cxc19 & Forward & AGTGTGGAGTCGAGGAACC \\
& Reverse & GAGTCCGGATCTAGGCAGG \\
Ifny & Forward & CCAAGTTGAGGTCAACAACCC \\
& Reverse & GGGACAATCTCTTCCCCACC \\
Tnfa & Forward & CCGATGGGTTGACCTTGC \\
& Reverse & CGGACTCCGCAAGTCTAAG \\
Ang1 & Forward & ATGGAAATTATACTCAGTGGCTGC \\
& Reverse & ATTAGTACCTGGTCTCAACATC \\
Tsp1 & Forward & TGTCACTGCCAGAACTCGGTA \\
& Reverse & GGAGACCAGCCATCGTCAG \\
Timp1 & Forward & GAGACACACCAGAGCAGATACC \\
& Reverse & GCTGGTATAAGGTGTCTCGT \\
\hline
\end{tabular}

flow analysis. For intracellular cytokine staining, 2 million cells were cultured in a 12-well plate for $4 \mathrm{~h}$ with Brefeldin A $(10 \mu \mathrm{g} / \mathrm{ml}$, eBiosciences), and then stained with the surface antibody mixture. After washed, intracellular staining was performed according to the manufacturer's instructions of a Fixation/Permeabilization Solution Kit (BD Bioscience). Flow cytometry data were acquired on a Gallios flow cytometer (Beckman) and analyzed with a Kaluza software (version 1.3). The following fluorescence-labeled or isotype-matched anti-mouse antibodies were used: Ly-6G-FITC, CD8-FITC, CD4-PE, NK1.1-APC-Cy7, Ly6C-PE, Gr1-APC-Cy7, IFN $\gamma$-PE-Cy7, and IFN $\gamma$-APC (BD Biosciences); F4/80-APC, CD45-BV421, and CD11b-BV 510 (BioLegend).

\section{In vivo IFNy neutralization}

When LAP0297 lung tumors reached 4-5 mm in diameter, mice bearing tumors were randomly divided into four groups, which were treated with an isotype-matched control rat IgG1 (clone HRPN, Bio-X Cell), $1 \mathrm{mg} / \mathrm{kg} \mathrm{LNT,}$ $250 \mu \mathrm{g}$ anti-IFNY antibody (clone XMG1.2, Bio-X Cell), or LNT plus an anti-IFN $\gamma$ antibody. LNT was administered into mice via i.p. injection every 3 days, while rat IgG1 or anti-IFN $\gamma$ antibody were given every 3 days. The treatment duration was 10 days.

\section{Enzyme-linked immunosorbent assay (ELISA)}

The concentrations of angiostatic factors IFN $\gamma, \mathrm{TNF} \alpha$, CXCL9, Ang1, TSP1, and TIMP1 in the tumor tissue lysate were measured according to the manufacturer's protocols by using the following mouse ELISA Kits: IFNY (Cat\#: DKW12-2000-096, Dakewe, Shanghai, China), TNF $\alpha$ (Cat\#: DKW12-2720-096, Dakewe, Shanghai, China), CXCL9 (Cat\#: 70-EK21432/2, MultiSciences, Hangzhou, China), Ang1 (Cat\#: DL-angpt1-mu-96 t), TIMP1 (Cat\#: DL-timp1-mu-96 t), and TSP1 (Cat\#: DL-thbs1-mu-96 t) from DLDEVELOP (Wuxi, China). Although different kits 
have different measure protocols, the major procedure is similar. Here, we used IFNY measurement as an example of the ELISA method. Briefly, IFN $\gamma$ standards, blank control and tested samples $(100 \mu \mathrm{l} /$ well $)$ were added into 96-well plates. Then Biotinylated antibody $(50 \mu \mathrm{l} /$ well $)$ was added to each well and incubated at $37{ }^{\circ} \mathrm{C}$ for 90 mins. After washing away unbound Biotinylated antibody, StreptavidinHRP $(100 \mu \mathrm{l} /$ well) was added to each well and incubated for 30 mins. After washing, TMB (100 $\mu \mathrm{l} /$ well) was added and incubated at $37{ }^{\circ} \mathrm{C}$ for 10 mins in the dark. The reaction was discontinued by the Stop solution and the optical density (OD) values were determined at the wavelength of $450 \mathrm{~nm}$ by a microplate reader. The concentrations of angiostatic factors were calculated using the standard curve's regression equation derived from standard absorbance values.

\section{Statistical analysis}

Statistical analyses were performed using a Prism statistical software (version 6, GraphPad Software, Inc.). Unpaired 2-tailed Student's $t$ tests were used to determine the statistical differences between two groups. One-way analysis of variance (ANOVA) was used to assess the differences when more than two groups were compared. Data were presented as mean \pm standard error of the mean (SEM). The results were considered as statistically significant at $P$ $<0.05\left(^{*}\right)$. $P$ values lower than 0.01 or 0.001 were indicated

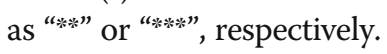

\section{Results}

LNT treatments exhibit better tumor growth inhibition at a relatively low dosage

Tumor immune evasion and tumor angiogenesis are two hallmarks of cancer $[2,22,25]$. LNT has been shown to suppress the growth of several types of cancer and the effects have been largely attributed to immune stimulation $[13,14,16,18,26,27]$. Whether LNT intervention influences tumor angiogenesis remains unclear. To determine the impact of LNT on tumor angiogenesis, we initially evaluated the dose effects of LNT treatments on LAP0297 lung carcinoma. We treated tumor-bearing mice with $0.25,0.5,1.0,2.0$, or $5.0 \mathrm{mg} / \mathrm{kg} \mathrm{LNT}$ for 10 days (Fig. 1a). All tested dosages of LNT treatments inhibited LAP0297 lung tumor growth, however, relatively lower doses exhibited better tumor control than higher doses, suggesting that LNT treatment inhibited tumor growth in an inverted U-shaped dose-response manner. Our data showed that the $1.0 \mathrm{mg} / \mathrm{kg}$ LNT treatments exhibited better antitumor effects, compared to the $5.0 \mathrm{mg} / \mathrm{kg}$ LNT treatments (Fig. 1b-c). Based on these results, we chose $1.0 \mathrm{mg} / \mathrm{kg}$ as the standard LNT treatment dose for LAP0297 lung tumors in the rest of this study. This unique dose effect of LNT was also observed in the CT26 colorectal cancer model, where
$1.0 \mathrm{mg} / \mathrm{kg}$ LNT treatments inhibited tumor growth, but $4.0 \mathrm{mg} / \mathrm{kg}$ LNT treatments did not affect tumor growth, again showing that a lower dose of LNT treatment has better antitumor effects (Additional file 1: Figure S1). Taken together, these data show that appropriately lower doses of LNT treatments exhibit better antitumor effects, compared to those of higher doses.

\section{LNT treatments reduce tumor vascular function in lung cancer}

We next investigated the effects of LNT treatments on tumor angiogenesis. Vessel density is a common parameter to evaluate the effects of an intervention on the tumor vasculature [22]. After 10 days of LNT treatments in the LAP0297 lung cancer model, vessel density in all of LNT-treated groups was comparable to the control group, even though tumors were smaller in LNT-treated groups when compared to the control group (Figs. 1 and 2 ). We then analyzed other parameters to get more information about the tumor vasculature. Interestingly, we found that LNT treatments suppressed tumor vascular function in an inverted U-shaped dose-response manner (Fig. 2). A relatively lower treatment dose of LNT $(1.0 \mathrm{mg} / \mathrm{kg})$ exhibited stronger antiangiogenic effects, compared to a relatively higher dose $(5.0 \mathrm{mg} / \mathrm{kg})$ (Fig. 2). Given that the tumor microenvironment is highly heterogeneous and tumor vessels are unevenly distributed $[28,29]$, we next looked at the whole images of the entire cross-sections of tumor tissues and analyzed the overall tumor vascular function. Again, the data showed that LNT treatments $(1.0 \mathrm{mg} / \mathrm{kg})$ decreased tumor vascular function (Fig. 3). To evaluate whether LNT treatments affect blood vessels in normal tissues, we examined blood vessels in colon tissues and found that LNT treatments didn't alter their vessel density or function (Additional file 1: Figure S2). Consistent to the reduction in tumor vascular function, the necrotic area in the LNT-treated group was increased compared to the control group (Additional file 1: Figure S3). Taken together, our data suggest that LNT treatments suppress tumor angiogenesis in the lung cancer model.

\section{LNT treatments suppress tumor vascular function in colorectal cancer}

To determine whether the antiangiogenic effects of LNT treatments are tumor-type dependent, we treated mice bearing CT26 colorectal cancer with LNT. Consistent with the effects seen in the LAP0297 lung cancer model, 10 days of LNT treatments $(1.0 \mathrm{mg} / \mathrm{kg})$ inhibited CT26 tumor growth (Additional file 1: Figure S1). We then analyzed the effects of LNT treatments on tumor angiogenesis. LNT treatments $(1.0 \mathrm{mg} / \mathrm{kg})$ significantly decreased the Ho33342 perfused tumor area, but did not change the density of tumor blood vessels (Fig. 4). The 


\section{a}

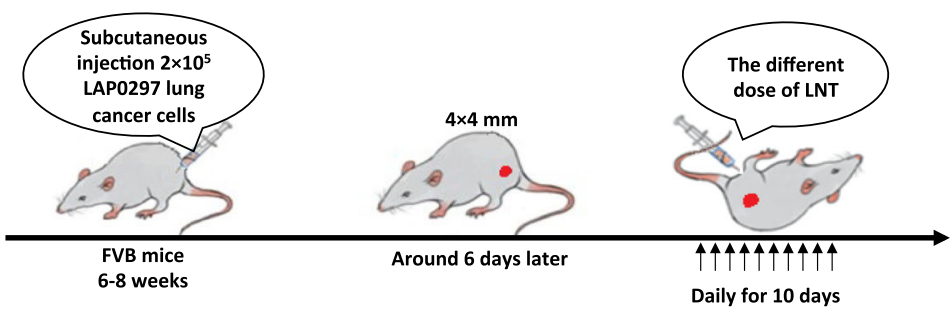

b
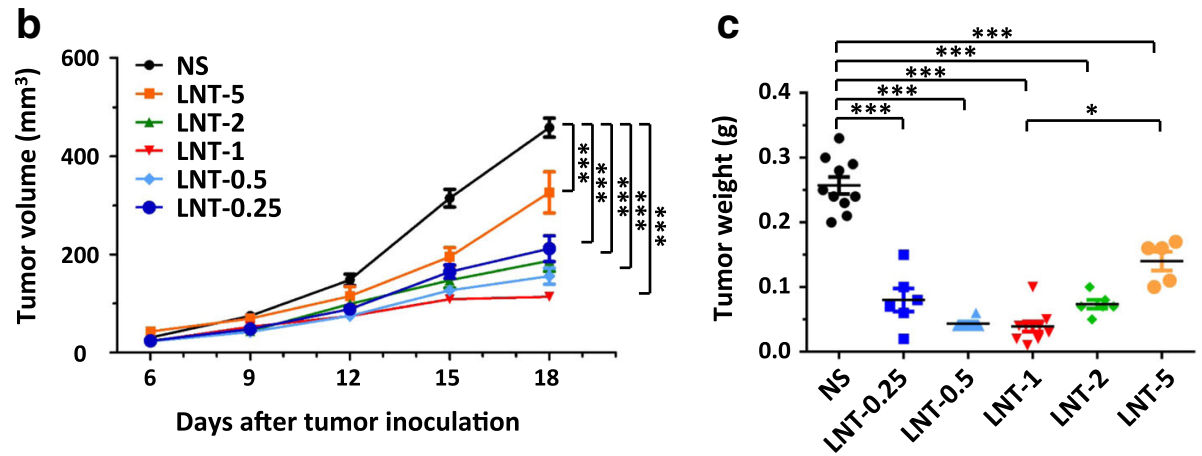

Fig. 1 Lentinan (LNT) exhibits better antitumor effects at a relatively lower dose compared with a higher dose. a Experimental design: FVB mice were subcutaneously (s.c.) inoculated with $2 \times 10^{5}$ LAP0297 lung cancer cells on the right flank. When tumors reached $4 \times 4 \mathrm{~mm}$ in diameter, mice were randomly divided into 6 groups and received i.p. injection of different doses of LNT $(0.25 \mathrm{mg} / \mathrm{kg}, 0.5 \mathrm{mg} / \mathrm{kg}, 1.0 \mathrm{mg} / \mathrm{kg}, 2.0 \mathrm{mg} / \mathrm{kg}, \mathrm{and} 5.0 \mathrm{mg} / \mathrm{kg})$ daily for 10 days. $\mathbf{b}$ LAP0297 lung tumor-bearing mice received different doses of LNT treatments. c Tumor weight was measured at the end of the treatments. NS: control group treated with saline. All data in this report are presented as means \pm SEM. ${ }^{*} p<0.05,{ }^{* *} p<0,01,{ }^{* * *} p<0.001$

a

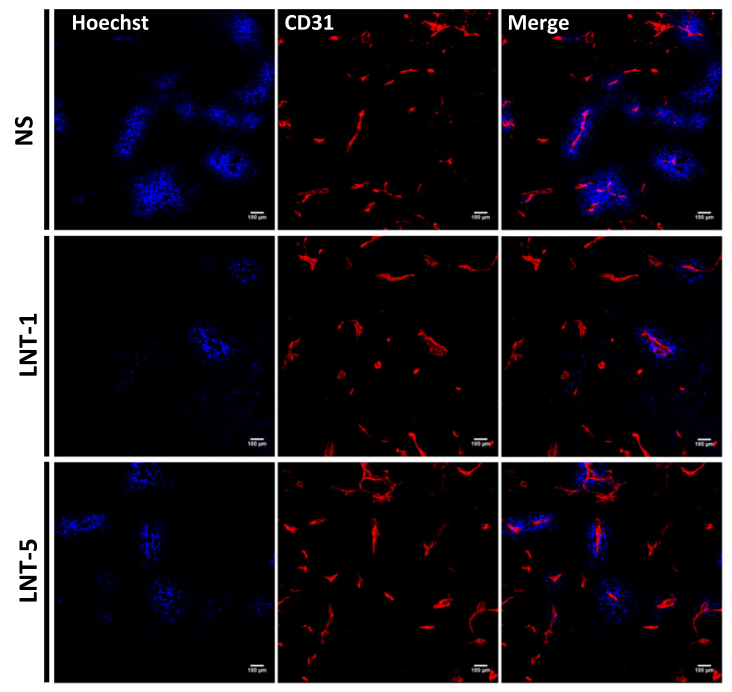

b

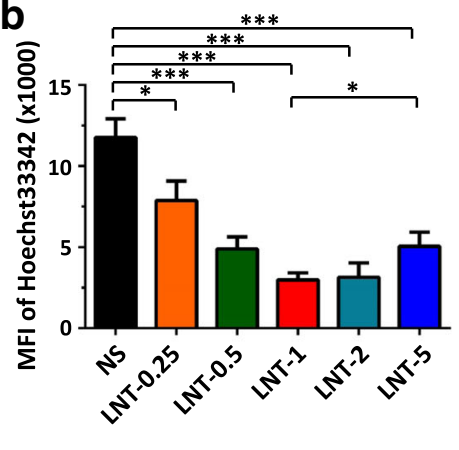

C

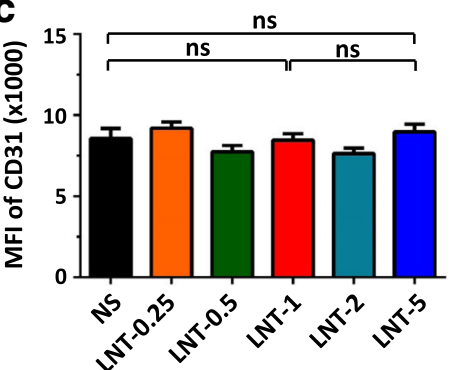

Fig. 2 LNT treatments reduce tumor vessel function in an inversed U-shaped dose-response manner. LAP0297 tumor bearing mice were treated with different doses of LNT for 10 days as described in Fig. 1. Tumor tissues were sectioned and stained with an anti-CD31 antibody. a Representative figures showing tumor vessel density and vascular function in NS control and LNT (1 and $5 \mathrm{mg} / \mathrm{kg}$ ) groups. $\mathbf{b}$ The mean fluorescence intensity (MFI) of CD31 (Red) and Hoechst 33342 (Blue) stained areas was quantified. CD31 is an endothelial cell marker. The intensity of Hoechst 33342 perfusion reflects the function of tumor vessels. ns: no significantly different, ${ }^{*} p<0.05,{ }^{* * *} p<0.001$ 


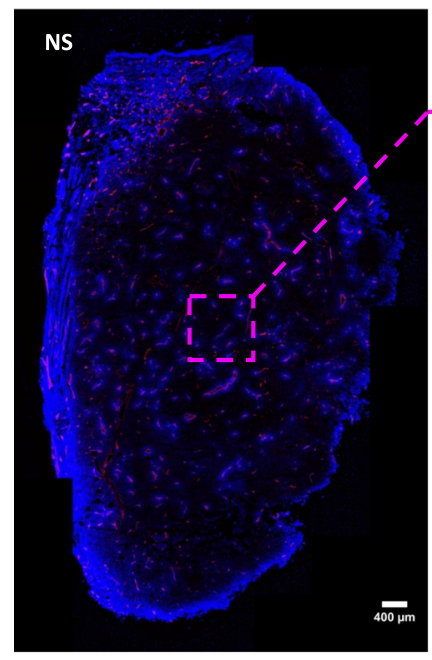

Blue: functional vessels

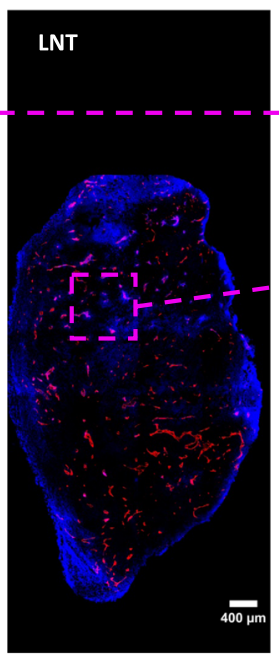

Red: total vessels

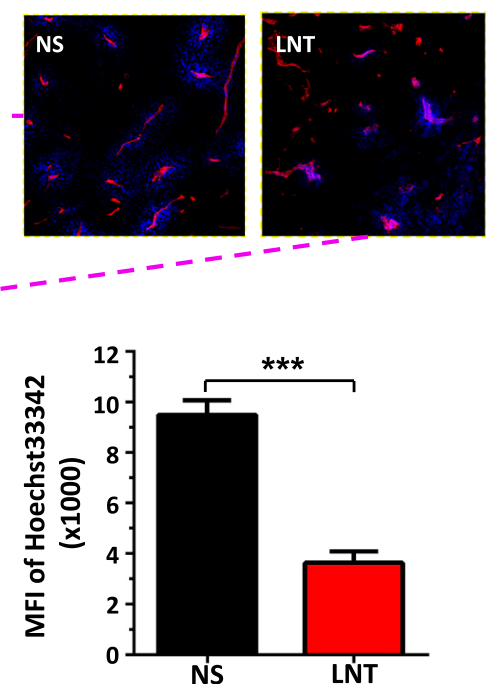

NS

Fig. 3 The whole images of tumor tissue cross-sections show reduced tumor vascular function after LNT treatments in LAP0297 lung cancer. LAP0297 tumor bearing mice received saline or LNT treatments (1.0 mg/kg) for 10 days as described in Fig. 1. Tumor tissues were sectioned and stained with an anti-CD31 antibody. The proportions of endothelial cell area (CD31, Red) and Hoechst 33342 (Blue) stained area over total tumor tissue area were quantified. CD31 is an endothelial cell marker. The intensity of Hoechst 33342 perfusion reflects the function of tumor vessels. *** $p<0.001$

data show that LTN treatments inhibit colorectal tumor vascular function, indicating that LNT can be used as an antiangiogenic agent for colorectal cancer treatment.

\section{Long-term LNT treatments induce the regression of lung cancer}

Antiangiogenic therapy is widely used in the clinic and shows modest antitumor efficacy in several cancer types, such as NSCLC and colorectal cancer. One crucial challenge for antiangiogenic therapy is the emergence of rapid drug resistance $[1,6,29]$. To determine the long-term antiangiogenic effect of LNT treatment, we continuously treated mice bearing LAP0297 lung cancer with LNT $(1.0 \mathrm{mg} / \mathrm{kg})$ for 1 month. During the LNT treatment course, the size of LAP0297 lung cancers persistently reduced and about $60 \%$ of tumors were completely regressed at the end of the treatment course (Fig. 5). We kept monitoring the tumor growth when LNT treatment was terminated, and found that there was no observed LAP0297 lung tumor regrowth 2 weeks post the LNT treatment course, and the percentage of tumor free mice reached 95\% (Fig. 5). These results suggest that long-lasting LNT treatments exhibit persistent antitumor effects in the LAP0297 lung cancer model.

\section{LNT treatments upregulate the expression of angiostatic factors}

To understand the mechanism of LNT inhibition against tumor angiogenesis, we performed endothelial cell tube formation assays, and found that LNT treatments did not directly affect endothelial cell tube formation (Additional file 1: Figure S4). We then analyzed the transcription of angiogenesis-related genes, and found that angiostatic genes, including interferon $\gamma$ (Ifn $\gamma$ ), tumor necrosis factor $\alpha$ (Tnfo), chemokine (C-X-C motif) ligand 9 (Cxcl9), Timp1, and Thrombospondin 1 (Tsp1), were up-regulated in LNT-treated tumors, compared to control tumors (Additional file 1: Figure S5). Moreover, we conducted ELISA to determine the protein levels of the angiostatic factors in the tumor microenvironment. The results demonstrated that LNT treatments $(1 \mathrm{mg} / \mathrm{kg})$ elevated the protein levels of IFN $\gamma$, TNF $\alpha$, CXCL9, and TIMP1 (Additional file 1: Figure S6). These data collectively suggest that LNT treatments induce the expression of angiostatic factors.

\section{LNT treatments increase IFNץ production in T cells and myeloid cells}

Since IFN $\gamma$ is often secreted by immune cell populations upon stimulation, we next analyzed the effects of LNT treatments on tumor-infiltrating immune cells. Flow cytometric analysis showed that LNT treatments facilitated tumor infiltration of $\mathrm{CD}_{4}^{+}, \mathrm{CD}^{+}, \mathrm{NK} 1.1^{+}$cells, monocytes, and neutrophils, while reducing tumor-associated macrophages (TAMs) (Fig. 6a). Intracellular staining further showed that LNT treatments increased the fractions of IFN $\gamma$-expressing $\mathrm{T}$ cells and NK cells, as well as IFN $\gamma$-expressing monocytes and neutrophils, but not TAMs (Fig. 6b). The data suggest that LNT treatments promote the accumulation of IFNy-expressing $\mathrm{T}$ cells and myeloid cells. 

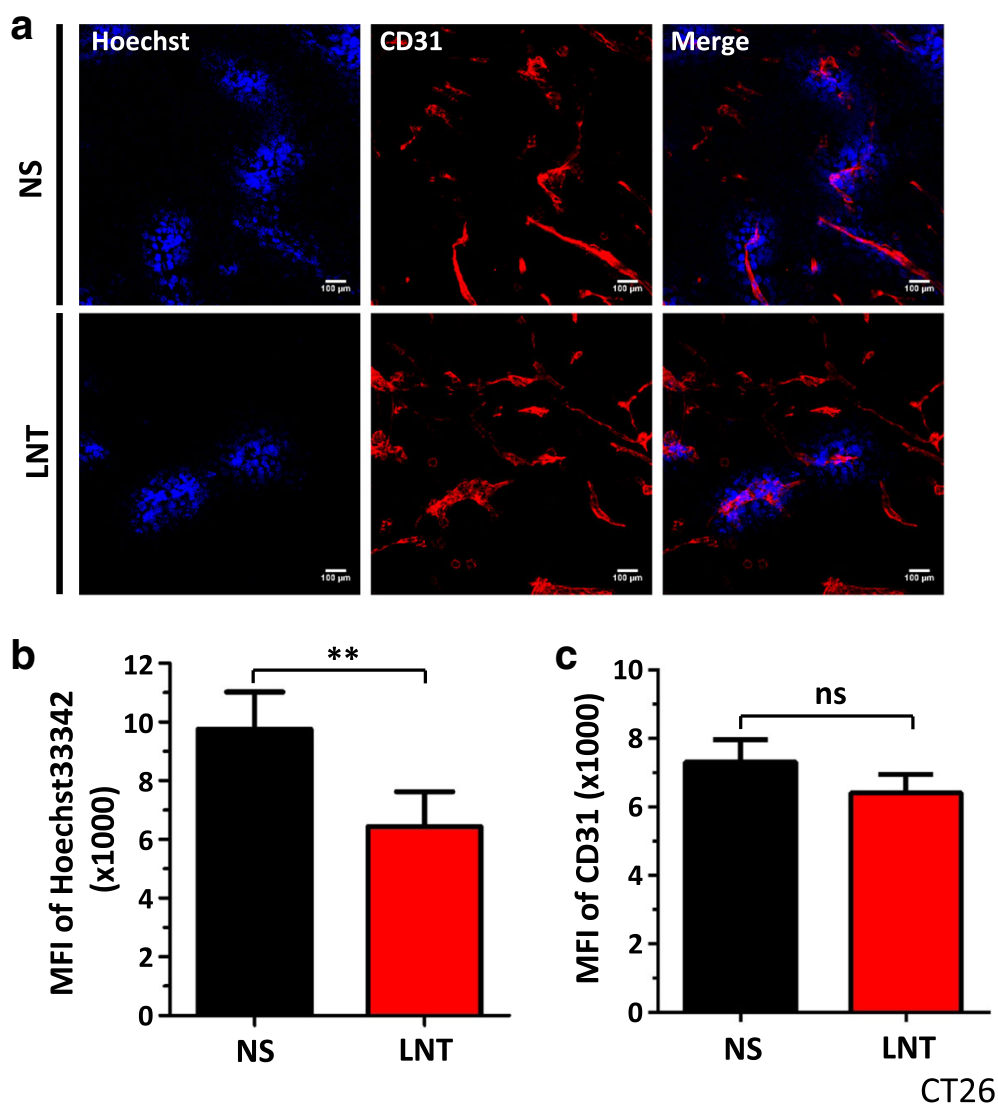

Fig. 4 LNT treatments significantly reduce tumor vascular function in CT26 colorectal carcinoma. CT26 colorectal carcinoma cells $\left(4 \times 10^{5}\right)$ were s.c. injected on the right flank of BALB/c mice. When tumors reached $4 \times 4 \mathrm{~mm}$ in diameter, mice were randomly divided into 2 groups and received i.p. injection of saline or $1.0 \mathrm{mg} / \mathrm{kg}$ of LNT for 10 days. Tumor vascular parameters were determined as described in Fig. 2. a Representative figures showed tumor vessel density and vascular function. $\mathbf{b}$ The quantifications of MFI of Hoechst33342 perfused tumor areas in saline (NS) or LNT treated tumors. c The MFI of tumor vessel density in saline or LNT treated tumors. ${ }^{* *} p<0.01$

IFN $\gamma$ is required for LNT treatment to reduce tumor vascular function

Previous studies have suggested that IFN $\gamma$-expressing $\mathrm{T}$ cells could suppress tumor angiogenesis [8, 12]. Together with the reports that LNT is commonly used as an immune modulator, and that $\mathrm{T}$ cells are often major antitumor immune effector cells [13, 14, 18, 28], we thus tested whether LNT exerts its antiangiogenic effects through T cells. We inoculated LAP0297 lung cancer cells in nude mice and then treated mice with $1.0 \mathrm{mg} / \mathrm{kg}$ LNT for 10 days as did in immune competent mice (Fig. 1). We found that LNT treatments inhibited the growth of LAP0297 lung cancer in nude mice (Additional file 1: Figure S7), but the degree of inhibition was less than that in immune competent mice (Fig. 1), indicating that $\mathrm{T}$ cells contribute to the inhibition of tumor growth by LNT treatments. This is consistent with the immunopotentiation of LNT. We also analyzed tumor vessels, and found that LNT treatments suppressed tumor vascular function in nude mice (Fig. 7), and that the degree of suppression was comparable to those of immune competent mice (Fig. 2). LNT treatments also slightly reduced tumor vessel density (Fig. 7), which was not observed in immune competent mice (Fig. 2). These data suggest that LNT treatments inhibit tumor angiogenesis in a $\mathrm{T}$ cell-independent manner.

A recent study demonstrated that elevated levels of IFN $\gamma$ arrested tumor blood flow without affecting tumor endothelial cell proliferation and apoptosis [10]. To further explore the relationship between IFN $\gamma$ and LNT treatment, we tested whether IFN $\gamma$ is responsible for the observed LNT-mediated suppression of vascular function. In vivo neutralization of IFNY partially reversed the inhibition of tumor growth by LNT treatments compared with the control group, while IFN $\gamma$ neutralization alone had little effect on tumor growth (Fig. 8a-b). Consistent with previous data, LNT treatments alone reduced tumor vascular function, and IFN $\gamma$ neutralization negated the effect of LNT treatments on tumor vascular function, indicating that IFN $\gamma$ mediates the impact of LNT treatments on tumor vascular function (Fig. 8). Taken together, these data suggest that LNT treatments 
a
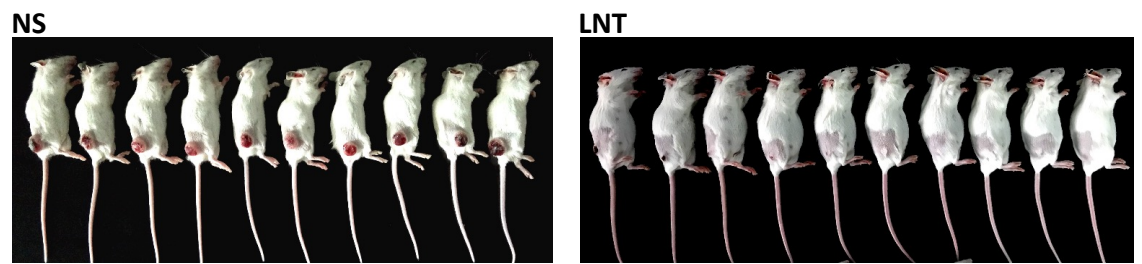

b

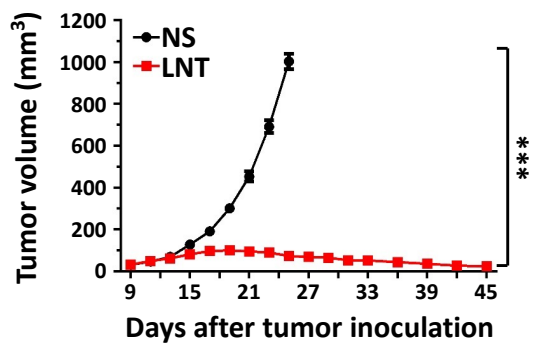

C

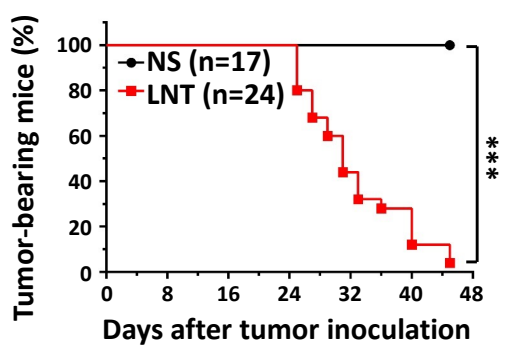

Fig. 5 Long-term LNT treatments induce regression of LAP0297 lung cancer. LAP0297 lung cancer-bearing mice were prepared as described in Fig. 1. When tumors reached $4 \times 4 \mathrm{~mm}$ in diameter, mice were randomly divided into 2 groups and received i.p. injection of saline or LNT (1.0 mg/kg) for 1 month. a Representative photographs of LAP0297 lung cancer-bearing mice in saline and LNT-treated group were taken at the end of the experiment. $\mathbf{b}$ The growth curves of LAP0297 lung cancer upon long-term therapy of saline or LNT. $\mathbf{c}$ The percentage of tumor-bearing mice on day 45 after tumor inoculation (NS group, $n=17$ mice, LNT-treated group, $n=24$ mice). ${ }^{* * *} p<0.001$

suppress tumor angiogenesis via IFNy and in a $\mathrm{T}$ cell-independent manner, which is correlated with an increase in IFN $\gamma$-expressing myeloid cells.

\section{Discussion}

Tumor initiation and progression relies on the formation of new blood vessels. Thus, the disruption of tumor blood vessels has the potential to inhibit tumor growth. However, the clinical benefits of antiangiogenic therapies are often in the order of weeks and rapidly developed drug resistance limits its long-term application [1, 6, 29]. In this study, we found that both of $\mathrm{T}$ cells and IFNy production contribute to tumor growth inhibition induced by LNT treatments, whereas IFN $\gamma$, but not T cells,
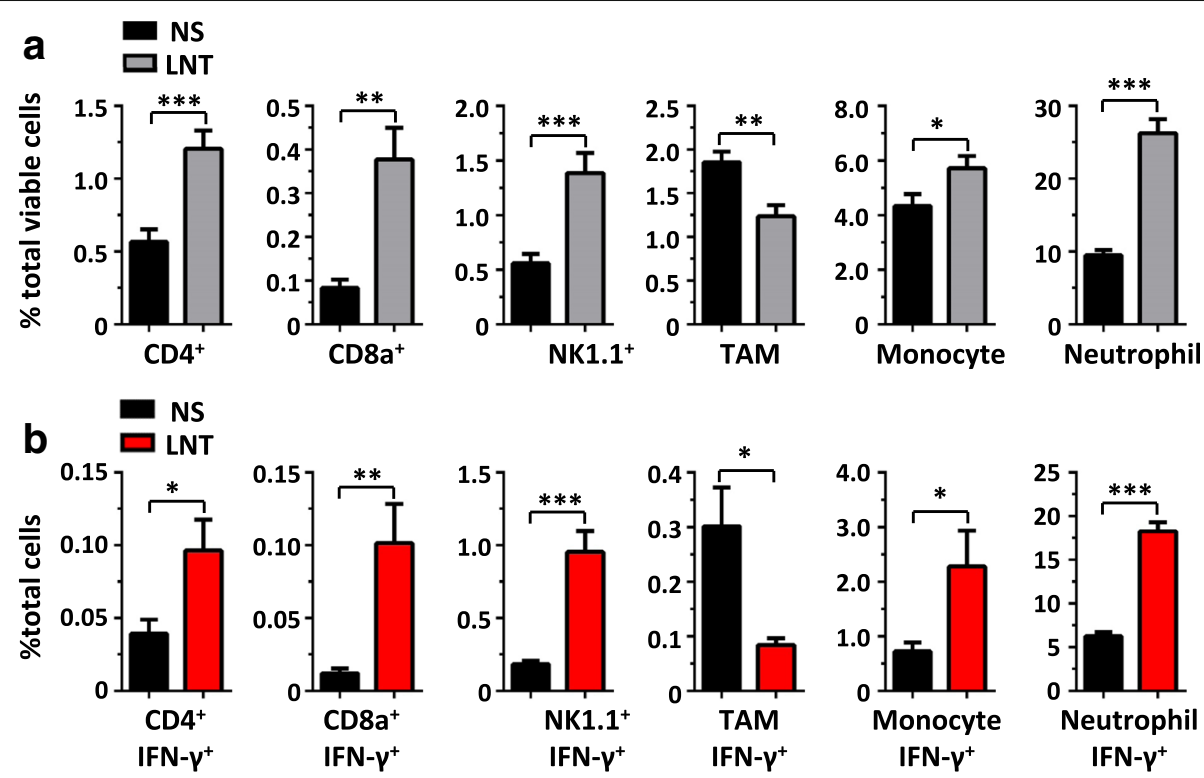

Fig. 6 LNT treatments promote tumor infiltration of IFNY-expressing T cells and myeloid cells. LAP0297 tumor bearing mice were prepared and then treated with saline or $1.0 \mathrm{mg} / \mathrm{kg}$ LNT for 10 days as described in Fig. 1. Tumor tissues were isolated and single cell suspensions were prepared for flow analysis. a Tumor infiltration of $\mathrm{T}$ cells and myeloid cells. $\mathbf{b}$ The proportions of IFNy-expressing $\mathrm{T}$ cells and myeloid cells in LAP0297 tumor tissues upon saline or LNT treatments. ${ }^{*} p<0.05,{ }^{* *} p<0,01,{ }^{* * *} p<0.001$ 

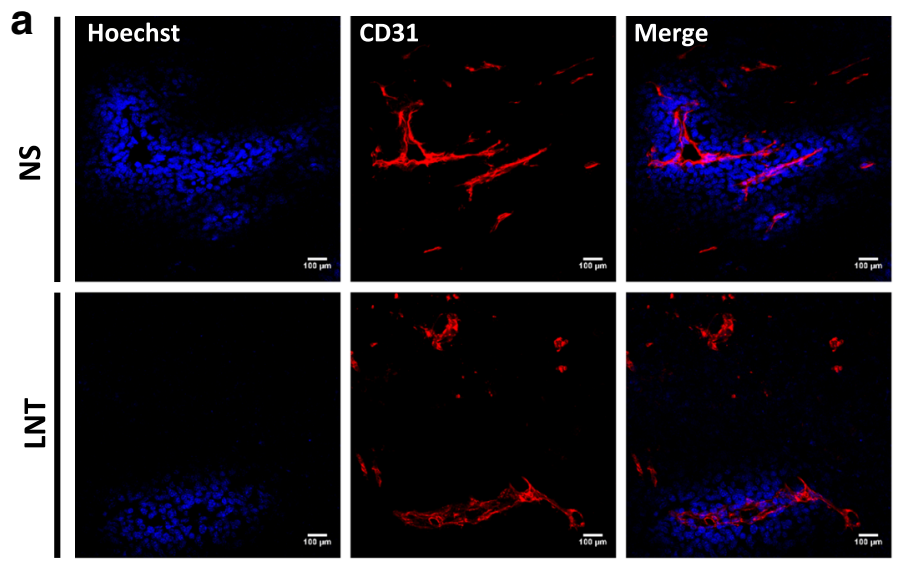

b
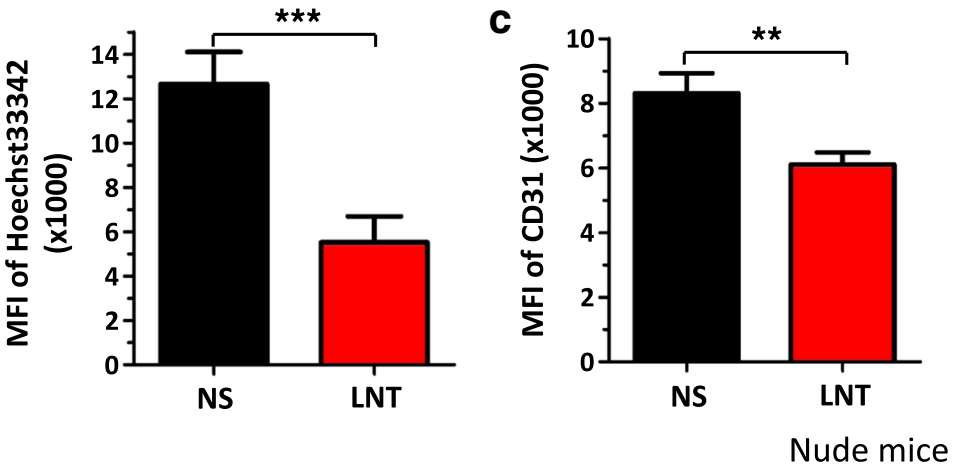

Fig. 7 LNT treatments reduce tumor vascular function in LAP0297 lung cancer in nude mice. Nude mice were s.c. inoculated with $2 \times 10^{5}$ LAP0297 lung cancer cells on the right flank. When tumors reached $4 \times 4 \mathrm{~mm}$ in diameter, mice were randomly divided into 2 groups and received i.p. injection of saline or $1.0 \mathrm{mg} / \mathrm{kg}$ of LNT for 10 days. Tumor vascular parameters were determined as described in Fig. 2. a Representative figures showing tumor vessel density and function. The MFI of Hoechst33342 perfused tumor areas $\mathbf{b}$ and the MFI of tumor vessel density $\mathbf{c}$ in saline or LNT treated tumors. ${ }^{* *} p<0.01,{ }^{* * *} p<0.001$

is required for the LNT-mediated antiangiogenic effect. Moreover, prolonged LNT treatments persistently suppressed tumor angiogenesis and reduced tumor volume. These results suggest that LNT could be served as a new antiangiogenic agent and may be suitable for long-term intervention.

LNT is a polysaccharide from the fruit body of $L$. edodes and has been used previously as a biological response modifier [14, 15, 30]. In particular, LNT has been approved as an adjuvant for the treatment of gastric cancer and brought clinical benefits to cancer patients [16, 31, 32]. LNT has demonstrated its antitumor effects in both primary and transplanted tumor models with negligible side effects $[17,33,34]$. Our data further suggest that LNT treatments decrease tumor vascular function, but do not affect vascular function in normal tissues. Such difference effects could be due to the fact that LNT treatments suppress tumor angiogenesis via increasing IFN $\gamma$ production, which is associated with the accumulation of IFN $\gamma$-expressing neutrophils. Normal tissues usually contain few neutrophils and will show minimal effects by LNT treatments. In addition, LNT could alleviate side toxicities of chemotherapeutic agents and potentially improve their efficacy $[26,35]$. The safety profiles of LNT as well as its ability to overcome the side effects of chemotherapy is superior to currently used traditional antiangiogenic drugs, providing new rationales for developing LNT as an antiangiogenic agent.

Blood vessel formation is tightly regulated by pro- and anti-angiogenic factors. The relentless production of pro-angiogenic factors promotes tumor vessel formation $[3,29]$. Thus antiangiogenic therapy is usually designed to suppress pro-angiogenic factors and inhibit tumor progression [1, 3]. Currently, antiangiogenic agents are used in the treatments of various types of solid cancers, such as NSCLC and colorectal cancer [1,3]. Therefore, we chose LAP0297 lung carcinoma and CT26 colorectal cancer as tumor models to evaluate the effects of LNT treatments on tumor angiogenesis. Although antiangiogenic therapy improves chemotherapy in several cancer types, the clinical benefits are marginal. One of the critical reasons is the development of drug resistance. Some tumors are intrinsic resistance to antiangiogenic therapy $[3,29]$. Some tumors respond to antiangiogenic therapy 


\section{a}

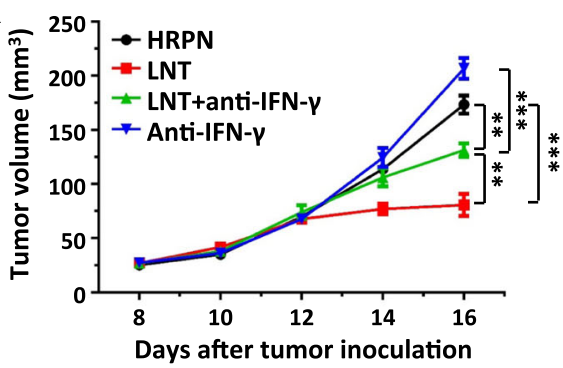

b

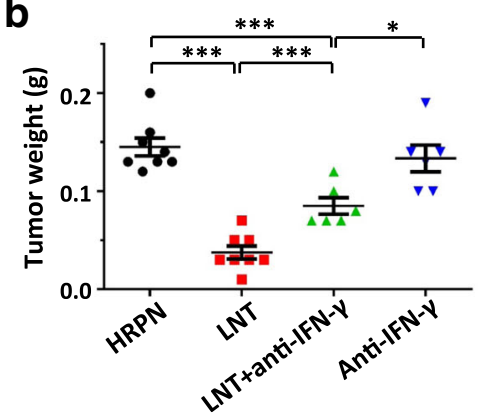

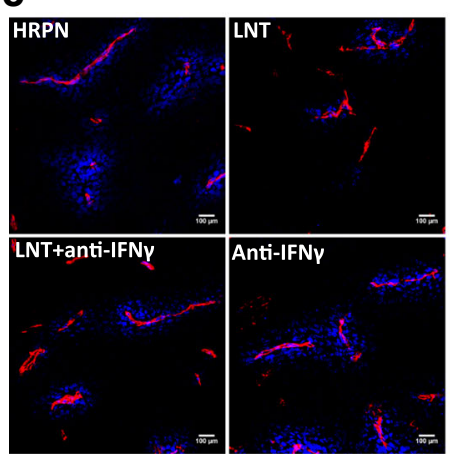

d
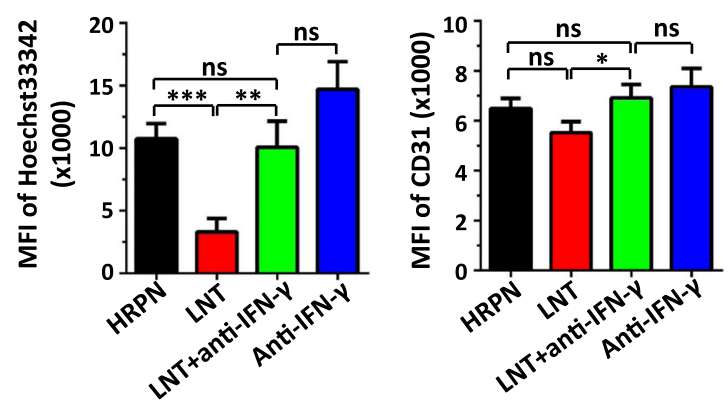

Fig. 8 Anti-IFN- $y$ antibody treatments reverse the effects of LNT treatments on tumor vessels in LAP0297 lung cancer. LAP0297 tumor bearing mice were prepared as described in Fig. 1. When tumors reached $4 \times 4 \mathrm{~mm}$ in diameter, mice were randomly divided into 4 groups and received i.p. injection of HRPN, LNT (1.0 mg/kg), anti-IFN- $\gamma$ antibody $(250 \mu \mathrm{g} / \mathrm{mouse})$ or LNT plus anti-IFN- $\gamma$ antibody for 10 days. Tumor vascular parameters were determined as described in Fig. 2. $\mathbf{a}$ and $\mathbf{b}$ The growth curves and weight of LAP0297 tumors treated with HRPN, LNT, anti-IFN- $\gamma$ antibody, or the combination of LNT and anti-IFN- $\gamma$ antibody. c Representative figures showing tumor vascular function and vessel density. $\mathbf{d}$ The quantifications of Hoechst33342 perfused tumor areas and tumor vessel density. ns: no significantly different, ${ }^{*} p<0.05,{ }^{* *} p<0.01,{ }^{* * *} p<0.001$

at the beginning, but develop drug resistance later on [1]. With antiangiogenic treatments being susceptible to the development of drug resistance, it is significant that we treated LAP0297 lung carcinoma with LNT for 1 month and did not observed drug resistance. Gene transcription and protein expression data showed that LNT treatments upregulated the levels of IFN $\gamma, \mathrm{TNF} \alpha$, CXCL9, and TIMP1. Among them, TIMP1 is an intrinsic angiostatic factor, while IFN $\gamma$, TNF $\alpha$, and CXCL9 are immune effector molecules with potent angiostatic activities. Whether or not elevated endogenous angiostatic factors will be less likely to cause drug resistance is not known, but the phenomenon is very interesting and worth further investigations.

Therapeutic antitumor drugs often suppress tumor growth in a dose-dependent manner. In general, higher dosages show better antitumor effect than that of lower dosages. The optimal therapeutic dosage is usually determined by the efficacy and toxicity of the drug. Interestingly, LNT inhibited tumor growth in an inversed U-shaped dose-response manner. Appropriately lower dose of LNT (such as $1.0 \mathrm{mg} / \mathrm{kg}$ ) showed better antitumor efficacy than that of higher dose (such as $5.0 \mathrm{mg} / \mathrm{kg}$ ). The exact underlying mechanism of this action is unknown. It could be due to the anti-angiogenic effects of LNT treatments. Our data showed that a relatively lower dose of LNT treatments (such as $1.0 \mathrm{mg} / \mathrm{kg}$ ) more potently reduced tumor vascular function than that of a relatively higher dose (such as $5.0 \mathrm{mg} / \mathrm{kg}$ ). Furthermore, our study suggests that LNT treatments $(1.0 \mathrm{mg} / \mathrm{kg})$ inhibit tumor vascular function via IFN $\gamma$ production and in a $\mathrm{T}$ cell-independent manner. In addition, LNT treatments $(1.0 \mathrm{mg} / \mathrm{kg})$ up-regulated IFNY production in several tumor-infiltrating myeloid cell populations. It is possible that the optimal treatment dose of LNT could be different for different populations of immune cells. The optimal treatment dose of LNT on a specific population of immune cells with respect to their quantity and function could be also different. Indeed, the $1.0 \mathrm{mg} / \mathrm{kg}$ treatment of LNT, but not the $5.0 \mathrm{mg} / \mathrm{kg}$ treatment of LNT, increased tumor infiltration of neutrophils (Additional file 1: Figure S8), which is the most abundant tumor-infiltrating myeloid cell population in LAP0297 lung carcinoma (Fig. 6a). Therefore, the optimal antitumor effects of LNT treatments seem to depend on the balance of vessel modulation and immune stimulation upon LNT treatments.

Since LNT treatment inhibits tumor growth in an inversed U-shaped dose-response manner, however, the lower or higher dose of LNT is relative and could be difficult to determine. This is an even bigger challenge in 
the clinic because different patients and different cancer types may have different sensitivities to LNT treatments. Our previous work suggests that monitoring vascular function could be used to predict the efficacy of immune checkpoint therapy [36]. In this study, our findings showed that a relatively lower dose of LNT treatments was more powerful than a higher dose in decreasing tumor vessel perfusion. Given that radiological methods have been developed to noninvasively measure vessel perfusion during anti-angiogenic therapy in the clinic $[37,38]$, it is conceivable that vessel perfusion monitoring could be adapted to determine the optimal dosage of LNT treatment.

LNT has been applied in some kinds of cancer treatments. Its antitumor effects are usually considered to be the result of its immune stimulation. Several recent studies suggested that LNT could induce tumor cell apoptosis, showing directly antitumor effect [30,39]. By using lung and colorectal cancer models, we showed that LNT treatments inhibited tumor angiogenesis via increased IFN $\gamma$ production in a $\mathrm{T}$ cell-independent manner. Taken together, LNT could affect tumor growth via multiple different mechanisms, including the modulation of immune system, the induction of tumor cell apoptosis $[13,14,16$, $18,30,39]$, and the suppression of tumor angiogenesis.

\section{Conclusions}

LNT treatments reduced tumor vascular perfusion and inhibited tumor growth in an inverted U-shaped dose-response manner. Furthermore, long-term LNT treatments continuously suppressed tumor angiogenesis and exhibited antitumor effects in LAP0297 lung tumor model. Mechanically, LNT decreased tumor vascular function by increasing IFN $\gamma$ production and in a $\mathrm{T}$ cell-independent manner, which was associated with the accumulation of tumor-infiltrating myeloid cells. Thus, this study suggests that LNT could be served as a new antiangiogenic agent for long-term cancer treatments.

\section{Additional file}

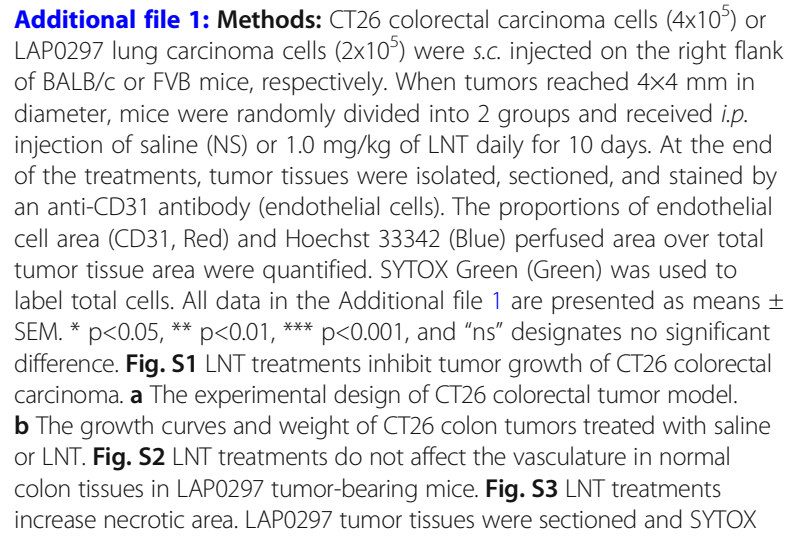

Green (Green) was used to label tumor tissue cells. Necrotic cells were relatively small, dense, and round. Fig. S4 LNT treatments do not affect endothelial cell tube formation in vitro. HUVECs were seeded on the top of growth factor reduced matrigel in a 24-well plate, and then incubated with different concentrations of LNT. The process of tube formation was monitored every $3 \mathrm{hrs}$ and pictures were taken at $12 \mathrm{hrs}$ after incubation with LNT. The tubes and branches in each well were counted. Fig. S5 LNT treatments upregulate the transcription of angiostatic factors, such as Ifny, Tnfa, CXC19, Angl, Timp1, and Tsp1, in LAP0297 tumor tissues. Fig. S6 LNT treatments increase the expression of angiostatic factors, such as IFNy, TNFa, CXCL9, Ang1, TIMP1, and TSP1, in LAP0297 tumor tissues. Fig. S7 LNT treatments inhibit tumor growth of LAP0297 lung cancer in nude mice. Nude mice were s.c. injected with $2 \times 10^{5}$ LAP0297 lung cancer cells on the right flank and treatments were performed as described in the above methods. Tumor sizes were measured every three days. Fig. S8 Relatively lower dose of LNT treatments (1 mg/kg), but not higher dosage $(5 \mathrm{mg} / \mathrm{kg}$ ), promotes the tumoral accumulation of neutrophils. LAP0297 tumor tissues were isolated and single cell suspensions were prepared. The tumor infiltration of leukocytes (CD45), neutrophils (Gr ${ }^{\text {hi }}$ ), and TAMs were determined by flow analysis. (ZIP $7212 \mathrm{~kb}$ )

\section{Abbreviations}

CXCL9: Chemokine (C-X-C motif) ligand 9; FGF: Fibroblast growth factor; IFNY: Interferon gamma; LNT: Lentinan; NSCLC: Non-small cell lung cancer; PDGF: Platelet-derived growth factor; PIGF: Placental growth factor; TIMP1: TIMP metallopeptidase inhibitor 1; TKI: Multiple targeted kinase inhibitors; TNFa: Tumor necrosis factor alpha; TSP1: Thrombospondin 1; VEGF: Vascular endothelial growth factor

\section{Acknowledgments}

The authors thank Dr. Wen Jiang of MD Anderson Cancer Center for critical reading and comments.

\section{Funding}

This work was supported in part by grants from the National Natural Science Foundation of China (81673004, 81372245), the fund of the Distinguished Professors of Jiangsu Province (SR21100114), the Collaborative Innovation Center of Hematology, and the Priority Academic Program Development of Jiangsu Higher Education Institutions.

\section{Availability of data and materials}

All data generated or analyzed during this study are included in this published article.

\section{Authors' contributions}

$\mathrm{YH}, \mathrm{QW}$, and $\mathrm{GZ}$ designed experiments, analyzed data and wrote the manuscript; SD, JK, PF, XW, ZP, DY, XZ, and XL performed experiments and analyzed data. QW and $\mathrm{YH}$ supervised the study. All authors read and approved the final manuscript.

\section{Ethics approval}

All animal works were approved by the Institutional Laboratory Animal Care and Use Committee of Soochow University. All of the procedures were performed in compliance with the Animal Care and Use Regulations of China.

\section{Consent for publication}

Not applicable.

\section{Competing interests}

Guoxi Zhang is an employee of Nanjing Luye Pharmaceutical Co., Ltd (Nanjing, China) and provided the main research subject (Lentinan) of the study. The other authors declare that they have no competing interests.

\section{Publisher's Note}

Springer Nature remains neutral with regard to jurisdictional claims in published maps and institutional affiliations.

\section{Author details}

${ }^{1}$ Cyrus Tang Hematology Center, Collaborative Innovation Center of Hematology, State Key Laboratory of Radiation Medicine and Prevention, Soochow University, 199 Ren-Ai Road, Suzhou 215123, Jiangsu, China. ${ }^{2}$ Nanjing Luye Pharmaceutical Co., Ltd, Nanjing 210061, Jiangsu, China. 
${ }^{3}$ Department of Traditional Chinese Medicine, Peking Union Medical College Hospital, Peking Union Medical College and Chinese Academy of Medical Sciences, No. 1 Shuaifuyuan, Dongcheng District, Beijing 100730, China.

Received: 1 April 2018 Accepted: 17 October 2018 Published online: 29 October 2018

\section{References}

1. Huang Y, Carbone DP. Mechanisms of and strategies for overcoming resistance to anti-vascular endothelial growth factor therapy in non-small cell lung cancer. Biochim Biophys Acta. 2015;1855:193-201.

2. Hanahan D, Weinberg RA. Hallmarks of cancer: the next generation. Cell. 2011:144:646-74.

3. Carmeliet $P$, Jain RK. Molecular mechanisms and clinical applications of angiogenesis. Nature. 2011;473:298-307.

4. Sandler A, Gray R, Perry MC, Brahmer J, Schiller JH, Dowlati A, Lilenbaum R, Johnson DH. Paclitaxel-carboplatin alone or with bevacizumab for nonsmall-cell lung cancer. N Engl J Med. 2006;355:2542-50.

5. Folkman J. Tumor angiogenesis: therapeutic implications. N Engl J Med. 1971:285:1182-6.

6. Park JS, Kim IK, Han S, Park I, Kim C, Bae J, Oh SJ, Lee S, Kim JH, Woo DC, He Y, Augustin HG, Kim I, Lee D, Koh GY. Normalization of tumor vessels by Tie2 activation and Ang2 inhibition enhances drug delivery and produces a favorable tumor microenvironment. Cancer Cell. 2017:31:157-8.

7. Janne PA, Gray N, Settleman J. Factors underlying sensitivity of cancers to small-molecule kinase inhibitors. Nat Rev Drug Discov. 2009;8:709-23.

8. Beatty G, Paterson Y. IFN-gamma-dependent inhibition of tumor angiogenesis by tumor-infiltrating CD4+ T cells requires tumor responsiveness to IFN-gamma. J Immunol. 2001;166:2276-82.

9. Hayakawa Y, Takeda K, Yagita H, Smyth MJ, Van Kaer L, Okumura K, Saiki I. IFN-gamma-mediated inhibition of tumor angiogenesis by natural killer Tcell ligand, alpha-galactosylceramide. Blood. 2002;100:1728-33.

10. Kammertoens T, Friese $C$, Arina A, Idel C, Briesemeister D, Rothe M, Ivanov A, Szymborska A, Patone G, Kunz S, Sommermeyer D, Engels B, Leisegang $M$, Textor A, Fehling HJ, Fruttiger M, Lohoff M, Herrmann A, Yu H, Weichselbaum R, Uckert W, Hübner N, Gerhardt H, Beule D, Schreiber H, Blankenstein T. Tumour ischaemia by interferon-gamma resembles physiological blood vessel regression. Nature. 2017;545:98-102.

11. Tian L, Goldstein A, Wang H, Ching Lo H, Sun Kim I, Welte T, Sheng K, Dobrolecki LE, Zhang X, Putluri N, Phung TL, Mani SA, Stossi F, Sreekumar A, Mancini MA, Decker WK, Zong C, Lewis MT, Zhang XH. Mutual regulation of tumour vessel normalization and immunostimulatory reprogramming. Nature. 2017;544:250-4.

12. Huang Y, Kim BYS, Chan CK, Hahn SM, Weissman IL, Jiang W. Improving immune-vascular crosstalk for cancer immunotherapy. Nat Rev Immunol. 2018;18(3):195-203.

13. Matsuoka H, Seo Y, Wakasugi H, Saito T, Tomoda H. Lentinan potentiates immunity and prolongs the survival time of some patients. Anticancer Res. 1997;17:2751-5

14. Ina K, Kataoka T, Ando T. The use of lentinan for treating gastric cancer. Anti Cancer Agents Med Chem. 2013;13:681-8

15. Xu X, Yan H, Tang J, Chen J, Zhang X. Polysaccharides in Lentinus edodes: isolation, structure, immunomodulating activity and future prospective. Crit Rev Food Sci Nutr. 2014:54:474-87.

16. Ren $L$, Perera $C$, Hemar $Y$. Antitumor activity of mushroom polysaccharides: a review. Food Funct. 2012;3:1118-30.

17. Suga T, Shiio T, Maeda $Y Y$, Chihara G. Antitumor activity of lentinan in murine syngeneic and autochthonous hosts and its suppressive effect on 3-methylcholanthrene-induced carcinogenesis. Cancer Res. 1984;44: 5132-7.

18. Zhou LD, Zhang QH, Zhang Y, Liu J, Cao YM. The shiitake mushroomderived immuno-stimulant lentinan protects against murine malaria bloodstage infection by evoking adaptive immune-responses. Int Immunopharmacol. 2009;9:455-62.

19. Israilides C, Kletsas D, Arapoglou D, Philippoussis A, Pratsinis H, Ebringerova A, Hribalova V, Harding SE. In vitro cytostatic and immunomodulatory properties of the medicinal mushroom Lentinula edodes. Phytomedicine. 2008;15:512-9

20. Sano B, Sugiyama Y, Kunieda K, Sano J, Saji S. Antitumor effects induced by the combination of TNP-470 as an angiogenesis inhibitor and lentinan as a biological response modifier in a rabbit spontaneous liver metastasis model. Surg Today. 2002;32:503-9.

21. Huang P, Duda DG, Jain RK, Fukumura D. Histopathologic findings and establishment of novel tumor lines from spontaneous tumors in FVB/N mice. Comp Med. 2008;58:253-63.

22. Huang Y, Yuan J, Righi E, Kamoun WS, Ancukiewicz M, Nezivar J, Santosuosso M, Martin JD, Martin MR, Vianello F, Vianello F, Leblanc P, Munn LL, Huang P, Duda DG, Fukumura D, Jain RK, Poznansky MC. Vascular normalizing doses of antiangiogenic treatment reprogram the immunosuppressive tumor microenvironment and enhance immunotherapy. Proc Natl Acad Sci U S A. 2012;109:17561-6.

23. Bodnar RJ, Yates CC, Wells A. IP-10 blocks vascular endothelial growth factor-induced endothelial cell motility and tube formation via inhibition of calpain. Circ Res. 2006;98:617-25.

24. Wang D, Wang H, Brown J, Daikoku T, Ning W, Shi Q, Richmond A, Strieter R, Dey SK, DuBois RN. CXCL1 induced by prostaglandin E2 promotes angiogenesis in colorectal cancer. J Exp Med. 2006;203:941-51.

25. Huang Y, Lin L, Shanker A, Malhotra A, Yang L, Dikov MM, Carbone DP. Resuscitating cancer immunosurveillance: selective stimulation of DLL1notch signaling in T cells rescues T-cell function and inhibits tumor growth. Cancer Res. 2011;71:6122-31.

26. Higashi D, Seki K, Ishibashi Y, Egawa Y, Koga M, Sasaki T, Hirano K, Mikami K, Futami K, Maekawa T, Sudo M. The effect of lentinan combination therapy for unresectable advanced gastric cancer. Anticancer Res. 2012;32:2365-8.

27. Yoshino S, Nishikawa K, Morita S, Takahashi T, Sakata K, Nagao J, Nemoto H, Murakami N, Matsuda T, Hasegawa H, Shimizu R, Yoshikawa T, Osanai H, Imano M, Naitoh H, Tanaka A, Tajiri T, Gochi A, Suzuki M, Sakamoto J, Saji S, Oka M. Randomised phase III study of S-1 alone versus S-1 plus lentinan for unresectable or recurrent gastric cancer (JFMC36-0701). Eur J Cancer. 2016; 65:164-71.

28. Huang Y, Goel S, Duda DG, Fukumura D, Jain RK. Vascular normalization as an emerging strategy to enhance cancer immunotherapy. Cancer Res. 2013: 73:2943-8.

29. Jain RK. Antiangiogenesis strategies revisited: from starving tumors to alleviating hypoxia. Cancer Cell. 2014;26:605-22.

30. Wang J, Li W, Huang X, Liu Y, Li Q, Zheng Z, Wang K. A polysaccharide from Lentinus edodes inhibits human colon cancer cell proliferation and suppresses tumor growth in athymic nude mice. Oncotarget. 2017;8:610-23.

31. Oba K, Kobayashi M, Matsui T, Kodera Y, Sakamoto J. Individual patient based meta-analysis of lentinan for unresectable/recurrent gastric cancer. Anticancer Res. 2009;29:2739-45.

32. Chihara G, Maeda Y, Hamuro J, Sasaki T, Fukuoka F. Inhibition of mouse sarcoma 180 by polysaccharides from Lentinus edodes (Berk.) sing. Nature. 1969:222:687-8.

33. Fujimoto K, Tomonaga M, Goto S. A case of recurrent ovarian cancer successfully treated with adoptive immunotherapy and lentinan. Anticancer Res. 2006;26:4015-8.

34. Hamuro J. Anticancer immunotherapy with perorally effective lentinan. Gan To Kagaku Ryoho. 2005;32:1209-15

35. Zhang $L$, Ji Q, Ni ZH, Sun J. Prohibitin induces apoptosis in BGC823 gastric cancer cells through the mitochondrial pathway. Asian Pac J Cancer Prev. 2012;13:3803-7

36. Zheng $X$, Fang $Z$, Liu $X$, Deng $S$, Zhou $P$, Wang $X$, Zhang $C$, Yin $R, H u$, Chen $X$, , Han Y, Zhao Y, Lin SH, Qin S, Wang X, Kim BY, Zhou P, Jiang W, Wu Q, Huang $Y$ : Increased vessel perfusion predicts the efficacy of immune checkpoint blockade. J Clin Invest 2018, 128:2104-2115.

37. Batchelor TT, Gerstner ER, Emblem KE, Duda DG, Kalpathy-Cramer J, Snuderl M, Ancukiewicz M, Polaskova P, Pinho MC, Jennings D, Plotkin SR, Chi AS, Eichler AF, Dietrich J, Hochberg FH, Lu-Emerson C, lafrate AJ, Ivy SP, Rosen BR, Loeffler JS, Wen PY, Sorensen AG, Jain RK. Improved tumor oxygenation and survival in glioblastoma patients who show increased blood perfusion after cediranib and chemoradiation. Proc Natl Acad Sci U S A. 2013;110:19059-64.

38. Emblem KE, Mouridsen K, Bjornerud A, Farrar CT, Jennings D, Borra RJ, Wen PY, Ivy P, Batchelor T, Rosen BR, Jain RK, Sorensen AG. Vessel architectural imaging identifies cancer patient responders to anti-angiogenic therapy. Nat Med. 2013:19:1178-83.

39. Gu YH, Belury MA. Selective induction of apoptosis in murine skin carcinoma cells $(\mathrm{CH} 72)$ by an ethanol extract of Lentinula edodes. Cancer Lett. 2005;220:21-8. 